\title{
Tuning of Composition and Morphology of LiFePO4 Cathode for Applications in All Solid-State Lithium Metal Batteries
}

\section{Erabhoina Harimohan}

University of Bayreuth

Mukundan Thelakkat ( $\square$ Mukundan.Thelakkat@uni-bayreuth.de)

University of Bayreuth

\section{Research Article}

Keywords:

Posted Date: January 13th, 2022

DOI: https://doi.org/10.21203/rs.3.rs-1246647/v1

License: (c) (i) This work is licensed under a Creative Commons Attribution 4.0 International License.

Read Full License 


\title{
Tuning of Composition and Morphology of $\mathrm{LiFePO}_{4}$ Cathode for Applications in All Solid- State Lithium Metal Batteries
}

\author{
Erabhoina Harimohan ${ }^{1,3}$, Mukundan Thelakkat ${ }^{1,2,3^{*}}$ \\ ${ }^{1}$ Applied Functional Polymers, Universitätsstraße.30, University of Bayreuth, Bayreuth 95447, \\ Germany \\ ${ }^{2}$ Bavarian Polymer Institute, Universitätsstraße.30, University of Bayreuth, Bayreuth 95447, Germany \\ ${ }^{3}$ Bavarian Centre for Battery Technology (BayBatt), Universitätsstraße.30, University of Bayreuth, \\ Bayreuth 95447, Germany \\ Corresponding author E-mail: Mukundan.Thelakkat@uni-bayreuth.de
}

\begin{abstract}
All solid-state rechargeable lithium metal batteries (SS-LMBs) are gaining more and more importance because of their higher safety and higher energy densities in comparison to their liquid-based counterparts. In spite of this potential, their low discharge capacities and poor rate performances limit them to be used as state-of-theart SS-LMBs. This arise due to the low intrinsic ionic and electronic transport pathways within the solid components in the cathode during the fast charge/discharge processes. Therefore, it is necessary to have a cathode with good electron conducting channels to increase the active material utilization without blocking the movement of lithium ions. Since SS-LMBs require a different morphology and composition of the cathode, we selected $\mathrm{LiFePO}_{4}$ (LFP) as a prototype and, we have systematically studied the influence of the cathode composition by varying the contents of active material LFP, conductive additives (super C65 conductive carbon black and conductive graphite), ion conducting components (PEO and LiTFSI) in order to elucidate the best ion as well as electron conduction morphology in the cathode. In addition, a comparative study on different cathode slurry preparation methods was made, wherein ball milling was found to reduce the particle size and increase the homogeneity of LFP which further aids fast Li ion transport throughout the electrode. The SEM analysis of the resulting calendered electrode shows the formation of non-porous and crack-free structures with the presence of conductive graphite throughout the electrode. As a result, the optimum LFP cathode composition with solid polymer nanocomposite electrolyte (SPNE) delivered higher initial discharge capacities of $114 \mathrm{mAh} g$ ${ }^{1}$ at $0.2 \mathrm{C}$ rate at $30^{\circ} \mathrm{C}$ and $141 \mathrm{mAh} \mathrm{g}^{-1}$ at $1 \mathrm{C}$ rate at $70{ }^{\circ} \mathrm{C}$. When the current rate was increased to $2 \mathrm{C}$, the electrode still delivered high discharge capacity of $82 \mathrm{mAh} \mathrm{g}^{-1}$ even after 500 cycle, which indicates that the optimum cathode formulation is one of the important parameters in building high rate and long cycle performing SS-LMBs.
\end{abstract}

\section{Introduction}

Although lithium-ion batteries (LIBs) have achieved impressive success in the past years, the energy density that is gradually approaching the theoretical limit in liquid electrolyte-based systems still cannot meet the actual requirements of electrical energy vehicles. Therefore, there is renewed interest in using pure lithium metal as anode, which necessitates the adaptation of electrolytes to mechanically stable solid-state electrolytes as well as cathodes towards all solid-state lithium metal batteries (SS-LMBs). This is based on the fact that the lithium anode in SS-LMBs can reach ultra-high theoretical specific capacity $\left(3860 \mathrm{mAh} \mathrm{g}^{-1}\right)$, low density $\left(0.53 \mathrm{~g} \mathrm{~cm}^{-3}\right)$ and lowest electrochemical potential (-3.04 V vs SHE). In addition to high energy density, the SS-LMBs can also assure high safety when compared to the conventional LIBs having flammable organic solvents ${ }^{1}$. In spite of this huge prospect, a rapid commercialization of SS-LMBs is still hindered due to issues such as their low ionic conductivity (presence of all solid components in the cell), low discharge capacity at higher current rates and poor cycle life ${ }^{1,2}$. Although a tremendous amount of work has been carried out on solid state electrolytes to improve their ionic conductivities, and chemical, mechanical and electrochemical stabilities within the operating potential window of the electrode ${ }^{1,3}$, less concentration has been paid on the engineering aspects of the cathode for SSLMBs.

Among all the cathode materials of lithium-ion battery (LIB) family, $\mathrm{LiFePO}_{4}$ (LFP) is one of the potential candidates from the application point of view due to its appreciably good theoretical discharge capacity of $170 \mathrm{mAh} / \mathrm{g}$, flat operating potential $\left(3.4 \mathrm{~V} \mathrm{vs} \mathrm{Li}^{+} / \mathrm{Li}\right)$, excellent reversibility, low cost, environmental benignity and high thermal and chemical stabilities ${ }^{4}$. Therefore, LFP is used as standard cathode material in the present study. Typically, the LFP content in the cathode used for liquid-based systems are in the range of $80-85 \mathrm{wt} \%{ }^{5-7}$. The high active material loading ends up with high porous structures in the electrode which leads to ohmic contact 
resistance and poor rate performance. Therefore, an optimum porosity was maintained in the electrode by calendaring process (densification of electrode) in order to have better contact between the particles as well as with minimum porosity for liquid electrolyte accessibility for Li ion movement during the redox process ${ }^{7}$. Though, the LFP cathode composition for the liquid-based systems is well studied and standardized in order to attain better electrochemical performance with good cycle stability ${ }^{8,9}$, the LFP cathode composition and morphology need to be varied to obtain the required compact (non-porous) morphology for SS-LMB. For example, the pores in the cathode have a negative impact on the electrochemical performance of SS-LMB, because the porous structures do not get filled with solid electrolytes, which in turn impede the lithium ion and electron percolation pathways.

In LIBs, the standard cathode composition consists of active material (for example; LFP), carbon black and polyvinylidene difluoride (PVDF) binder ${ }^{6}$. However, the same composition cannot be suitable for SS-LMBs because the cathode needs both ion and electronic conducting mediums in it (scheme 1). In general, the cathodes used for PEO-based systems that are reported in the literature have different amounts of active material, ion and electron conductive additives as electrode composition ${ }^{10-12}$. For example, Wan et al ${ }^{10}$ reduced the LFP content to $60 \mathrm{wt} \%$ and obtained a stable discharge capacity of $\sim 100 \mathrm{mAh} \mathrm{g}^{-1}$ even after 300 cycles at $0.5 \mathrm{C}$ at $60{ }^{\circ} \mathrm{C}$. This is supported by later studies, which also used 60-70 wt\% of LFP for a stable electrochemical performance ${ }^{12-14}$. Though, the cells fabricated by these electrodes exhibited good electrochemical performance, the reason for selecting a particular composition to obtain optimum amount of each component in the cathode as well as its consequence on morphology is not reported, which motivated us to study the influence of composition and morphology on the electrochemical performance of the LFP cathode during higher C rates. It is also reported in the literature that the addition of PEO in the cathode has multifunctional effects such as it enhances the ionic conductivity via hopping mechanism ${ }^{1}$, acts as binder for all the components in the electrode and also helps in integrating both the cathode and electrolyte layers to form a stable structure ${ }^{15}$. However, the electronic conductivity is mainly dependent on the type of conductive additives used, which plays an important role in enhancing the overall electrochemical performance such as rate capability and cycle stability of the cathode material. Recently, Ann et $\mathrm{al}^{16}$, has studied the effect of binary conductive additives such as vapor grown carbon fibers (VGCF) and Super P carbon on the electrochemical performance of layered cathode $\left(\mathrm{LiNi}_{0.6} \mathrm{Co}_{0.2} \mathrm{Mn}_{0.2} \mathrm{O}_{2}\right)$ material for SS-LMBs. They concluded that the presence of fibrous VGCF with intact nanostructured carbon particles and active material in the cathode increases the rate performance of the cell due to continuous electron conduction networks. Therefore, it is desirable to choose the conductive additive, which can improve the electrical conductivity at high current rates and should be of low cost from the commercial point of view.

In addition to electrode composition, it is challenging to prepare the cathode electrode for SS-LMBs with non-porous structure for better ion conduction during the fast reaction kinetics and also the homogenous distribution of active material and conductive particles within the binder matrix for good electron transport pathways ${ }^{17}$. In general, liquid-based slurry casting process is the most commonly used method reported in the literature for the fabrication of cathode in SS-LMBs ${ }^{13,14}$. As a result of this, the mechanical contact among the active material, conductive additive and the binder increases, which leads to enhanced electrochemical performance. Furthermore, it is also reported that the particle size of the active material also plays an important role in improving the electrical conductivity and overall electrochemical performance in SS-LMBs ${ }^{18,19}$, paving the way for slurry preparation processes. For instance, Strauss et $\mathrm{al}^{19}$ studied the influence of particle size on the electrochemical behaviour of layered cathode ranging from $4.8 \mu \mathrm{m}$ to $15.6 \mu \mathrm{m}$. The cell with cathode material of small particle size delivered high discharge capacity of $162 \mathrm{mAh} \mathrm{g}^{-1}$ in comparison to the cathode with big particle size $\left(84 \mathrm{mAh} \mathrm{g}^{-1}\right)$ and they have concluded that the smaller particles provide better electron percolation pathways within the cathode during the redox process. Another report states that the large active material particle size in the electrode require high content of conductive additive in order to provide continuous electron percolation pathways ${ }^{20}$. Hence considering all these aspects, it is necessary to have a comprehensive understanding of how the cathode components, slurry preparation method and calendaring process influences the quality of the electrode in building high performing batteries in order to meet the requirements of advanced electronics as well as EV applications. Such a systematic and comprehensive study using LFP as a prototype cathode material brings very useful information for the scientific community to create new compositions as well as new systems with any novel cathode material for SS-LMBs.

Herein, we studied the influence of lithium salt concentration, conductive additives, morphology and electrode composition on the electrochemical performance of LFP cathode (as a prototype material) for all SSLMBs. As electrolyte, we selected a solid polymer nanocomposite electrolyte (SPNE), PEO/LiTFSI (EO/Li = 20) containing $10 \mathrm{wt} \%$ of $\mathrm{TiO}_{2}$ nanoparticles. Initially, morphological studies were made on electrode to study how calendaring process helps in densifying the electrode to form non-porous structure and its influence on rate performance in a battery. A comparative study on ball milling vs conventional magnetic stirring based slurry preparation processes give an insight on the effect of particle size and their impact on the electrochemical performance of LFP cathode. Furthermore, a systematic study on cathode composition by varying EO/Li ratios of 
PEO/LiTFSI, super C65 conductive carbon black vs conductive graphite and active material provide better understanding about the electrochemical behaviour of individual components and the corresponding content in the cathode. As a result, the cathode composition of LFP-5 (with an electrode composition of LFP : CB : CG : PEO : LITFSI $=63: 4.9: 2.1: 19.4: 10.6$, where CB and CG stand for super C65 conductive carbon black and conductive graphite, respectively) cells delivered the highest discharge capacities at $30{ }^{\circ} \mathrm{C}$ and $70{ }^{\circ} \mathrm{C}$ with good stability upto 50 cycles. Finally, we also studied how the thickness of SPNE influences the discharge capacity of LFP-5 cathode at high current rates.

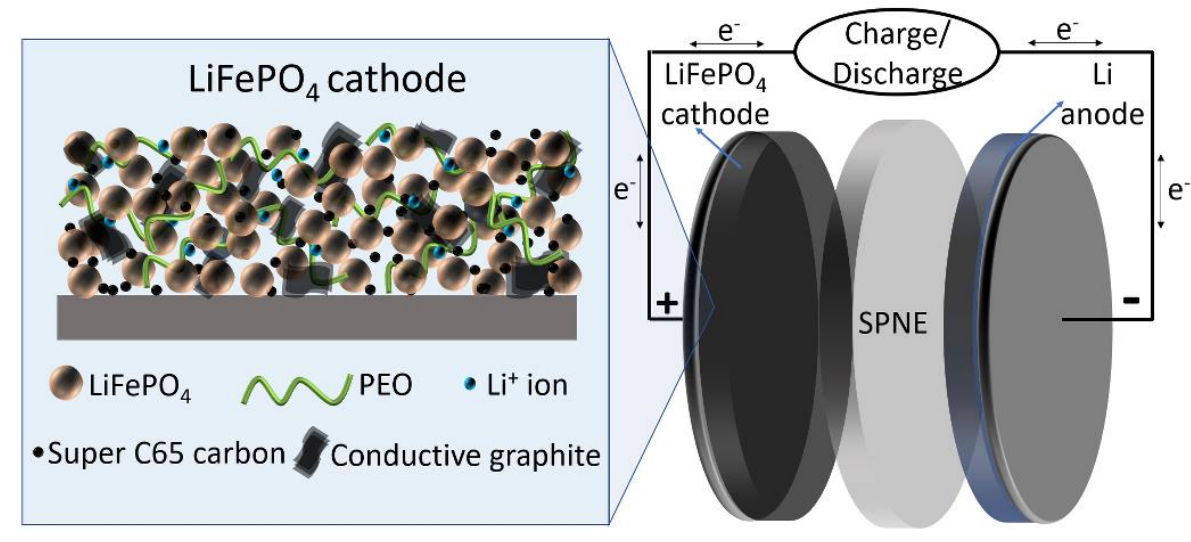

Scheme 1. Schematic illustration of uniformly distributed cathode components (left) and all solid-state lithium metal battery SS-LMB (right).

\section{Results and Discussion}

In order to understand the electrochemical behaviour of cathode, the other components in a battery such as electrolyte (SPNE) and lithium metal anode are used as a reference standard throughout the measurements. The $\mathrm{EO} / \mathrm{Li}$ ratio of PEO/LiTFSI is maintained as 20:1 according to the literature report ${ }^{21}$, due to its good mechanical stability, high lithium ion transport number and high ionic conductivity. To start with, the cathode composition was adapted from the reported literature, wherein Judez et al. have used $63 \mathrm{wt} \%$ of LFP as active material ${ }^{21}$. Thus the first LFP cathode (LFP-1) has a wt\% composition of LFP : CB : PEO : LiTFSI = $63: 7: 22.7: 7.3$, where CB stands for super C65 conductive carbon black (see table 1).

Importance of calendaring process on morphology of LFP cathode: The LFP-1 slurry prepared by magnetic stirring was coated on to carbon-coated aluminium foils, dried and subjected to calendaring process. These LFP-1 cathode layers with and without calendaring was subjected to SEM analysis in order to understand the morphology, porosity and distribution of active particles in the cathodes. Figure 1a and $1 \mathrm{~b}$ are the SEM images of LFP-1 before and after calendaring process. Both uncalendered and calendered electrodes show large agglomerated LFP particles with non-uniform distribution. However, the uncalendared electrode displays high porosity and cracks in the electrode, which were reduced after calendaring process (Figure S1). The dense structure provides all the components in the electrode to be intact and that helps in better ion and electron conduction pathways during the redox process. Furthermore, the cross-sectional SEM images of uncalendered LFP-1 (figure 1c) shows an uneven surface, whereas the calendered electrodes (figure 1d) shows smooth surface. The flat and smooth surface of the electrode is expected to reduce the interfacial resistance between the cathode and electrolyte layers during cycling process. The influence of calendaring the electrode was clearly observed during the rate capability measurements as shown in the figure $1 \mathrm{e}$ and $1 \mathrm{f}$. At $0.1 \mathrm{C}$, both the cells delivered comparable initial discharge capacity (uncalendered LFP-1 $=119 \mathrm{mAh} \mathrm{g}^{-1}$; calendered LFP-1 $=121 \mathrm{mAh} \mathrm{g}^{-1}$ ) at $70^{\circ} \mathrm{C}$. However, a huge difference is observed with increase in the current rate to $1 \mathrm{C}$. The calendered LFP-1 cell delivered $82 \mathrm{mAh} \mathrm{g}^{-1}$ in comparison to the uncalendared electrode $\left(47 \mathrm{mAh} \mathrm{g}^{-1}\right)$. Moreover, the uncalendared electrode displays large overpotential (figure 1f) indicating that the porous structures in the cathode reduces the lithium ion movement during fast reaction kinetics. Thus, a densification and decrease in porosity is the first requirement for SS-LMBs. Henceforth, all the cathodes were calendered before their electrochemical measurements. 

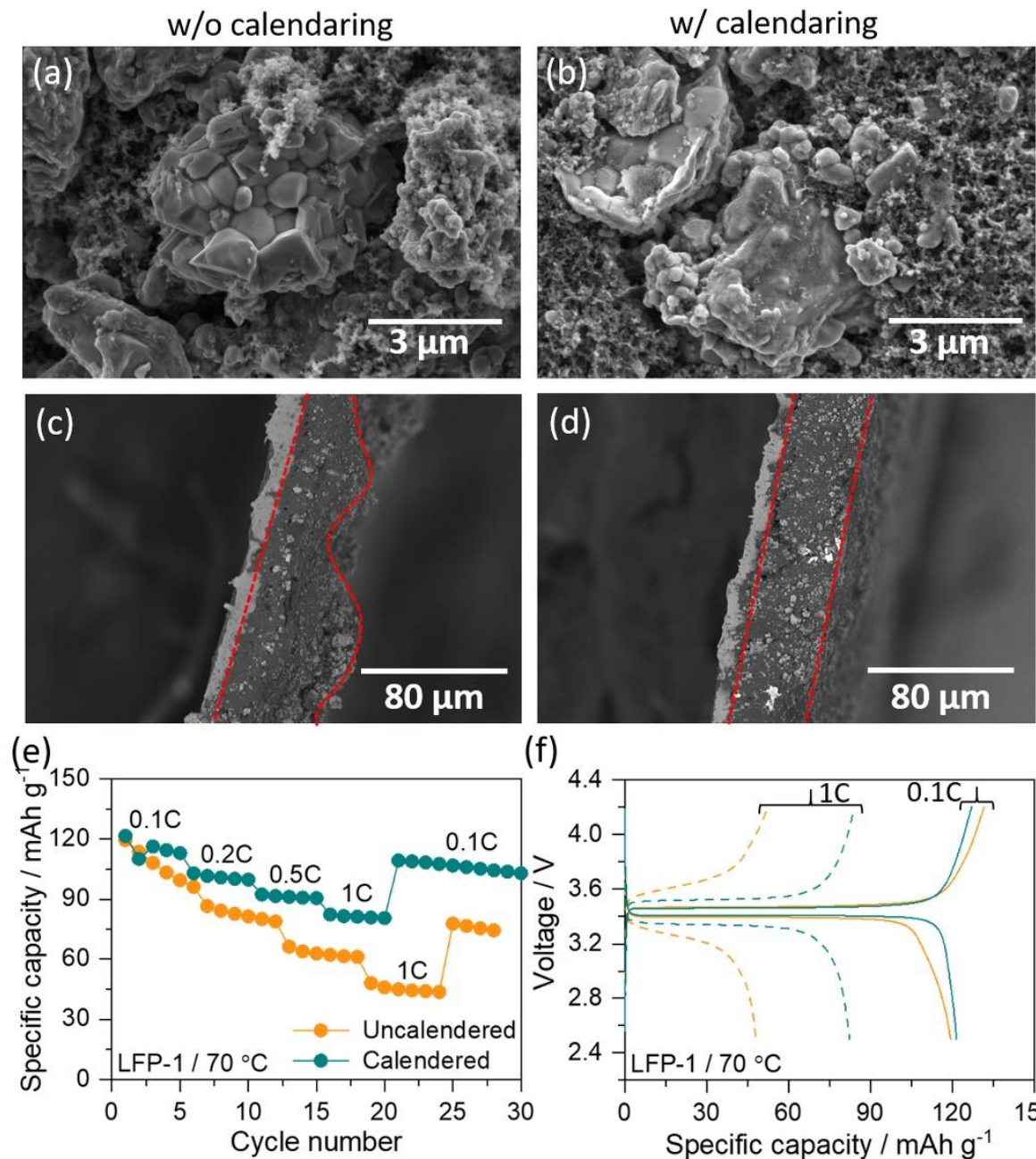

(f)

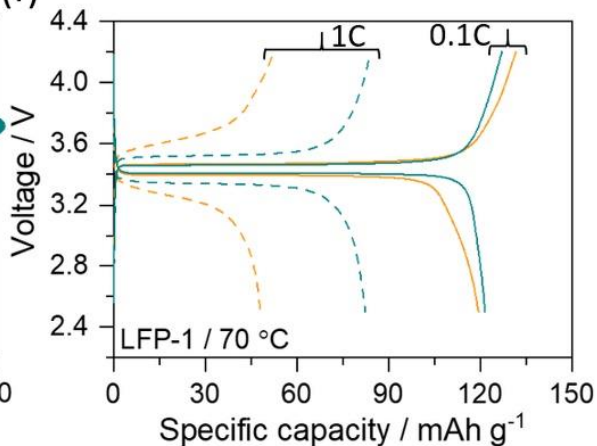

Figure 1. (a) and (b) are the SEM images, (c) and (d) are the cross-sectional SEM images of LFP-1 cathode before and after calendaring process, (e) comparative rate capability curve and (f) the corresponding charge/discharge curves of LFP-1 measured at $70{ }^{\circ} \mathrm{C}$ at different current rates, from $0.1 \mathrm{C}$ to $1 \mathrm{C}$.

Variation of Li salt content: The lithium salt content in the cathode can influence the discharge capacity and also the cyclic stability during repeated charge/discharge processes. To verify and understand the necessity and influence of Li-salt content in cathode, the LFP content was kept constant (63 wt\%) and the three different weight ratios of PEO:LiTFSI were selected during the preparation of cathode slurry which corresponds to the EO/Li ratios of 20:1 (LFP-1), 16:1 (LFP-2) and 12:1 (LFP-3), respectively (Table 1). It is to be noted that the PEO with different salt contents show semicrystalline behavior with decreasing crystallinity on increasing salt content (see figure S2). All the slurries were prepared by magnetic stirring process. Figure 2a shows the comparative rate capability curves of LFP-1 to LFP-3 electrodes measured at different current rates ranging from $0.1 \mathrm{C}$ to $1 \mathrm{C}$ at $70{ }^{\circ} \mathrm{C}$. It is interesting to note that the capacity of the cell increases with increasing-lithium salt content in the electrode and the resulting cells with LFP-1, LFP-2 and LFP-3 electrodes delivered high initial discharge capacities of $121 \mathrm{mAh}$ $\mathrm{g}^{-1}, 138 \mathrm{mAh} \mathrm{g}^{-1}$, and $149 \mathrm{mAh} \mathrm{g}^{-1}$, respectively. Even at high current rate of 1C the electrodes delivered an appreciated discharge capacity of $82 \mathrm{mAh} \mathrm{g}^{-1}, 99 \mathrm{mAh} \mathrm{g}^{-1}$ and $107 \mathrm{mAh} \mathrm{g}^{-1}$ and retained the capacities of 103 $\mathrm{mAh} \mathrm{g}{ }^{-1}, 118 \mathrm{mAh} \mathrm{g}^{-1}$, and $126 \mathrm{mAh} \mathrm{g}^{-1}$, respectively, when the current rate is reversed back to $0.1 \mathrm{C}$. In the present study, we limited the $\mathrm{EO} / \mathrm{Li}$ ratio to $12: 1$, because it is reported that the increased $\mathrm{EO} / \mathrm{Li}$ ratio beyond eutectic (9:1) leads to phase segregation which may leads to poor cycle performance ${ }^{22}$. Thus, the EO/Li ratio of 12:1 is selected as optimum content during the preparation of cathodes. Figure $2 \mathrm{~b}$ shows a typical charge/discharge profile of the corresponding LFP-3 electrode. The charge/discharge profile show a clear plateau around 3.45V which represents the typical redox behavior of LFP cathode ${ }^{4}$. The high discharge capacity of LFP-3 is mainly due to sufficient lithium ion concentration, non-porous and crack free structure of the electrode which increases both the ion and electron conduction pathways at high current rate (1C). As already mentioned in the introduction that the large particle size of active material has huge negative impact on the electrochemical properties due to limited lithium ion diffusion into the solid-state agglomerated particles. A similar behavior is also observed in the present study, with increasing the current rate the discharge capacity decreases owing to nonhomogeneous distribution of 
agglomerated LFP particles in the cathode (supported by the SEM analysis). Therefore, the slurry preparation process may play an important role to decrease the LFP particle size and improve the homogeneity to achieve an enhanced electrochemical performance of the cell.

Table 1. Influence of EO:Li ratio in LFP cathode on electrochemical performance. The batteries were tested at different $\mathrm{C}$ rates (ranging from $0.1 \mathrm{C}$ to $1 \mathrm{C}$ ) at $70{ }^{\circ} \mathrm{C}$ for 30 cycles using Li/SPNE/LFP configuration.

\begin{tabular}{|c|c|c|c|c|c|}
\hline \multirow{2}{*}{$\begin{array}{c}\text { Sample } \\
\text { LFP-1 }\end{array}$} & \multicolumn{2}{|c|}{ Cathode composition } & \multirow{2}{*}{$\begin{array}{l}\text { Method } \\
\text { Magnetic stirring }\end{array}$} & \multirow{2}{*}{$\begin{array}{l}\text { EO:Li ratio } \\
20: 1\end{array}$} & \multirow{2}{*}{$\frac{\begin{array}{c}\text { Capacity } \\
\left(\mathrm{mAh} \mathrm{g}^{-1}\right)\end{array}}{82(1 \mathrm{C})}$} \\
\hline & LFP : CB : PEO : LiTFSI & $63: 7: 22.7: 7.3$ & & & \\
\hline LFP-2 & LFP : CB : PEO : LiTFSI & $63: 7: 21.4: 8.6$ & Magnetic stirring & $16: 1$ & $99(1 \mathrm{C})$ \\
\hline LFP-3 & LFP : CB : PEO : LiTFSI & $63: 7: 19.4: 10.6$ & Magnetic stirring & $12: 1$ & $107(1 \mathrm{C})$ \\
\hline
\end{tabular}

(a)

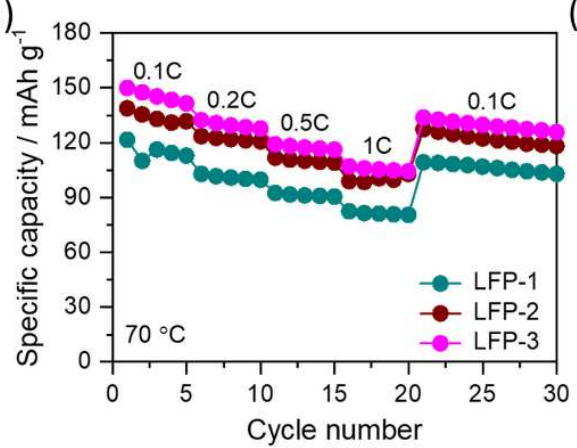

(b)

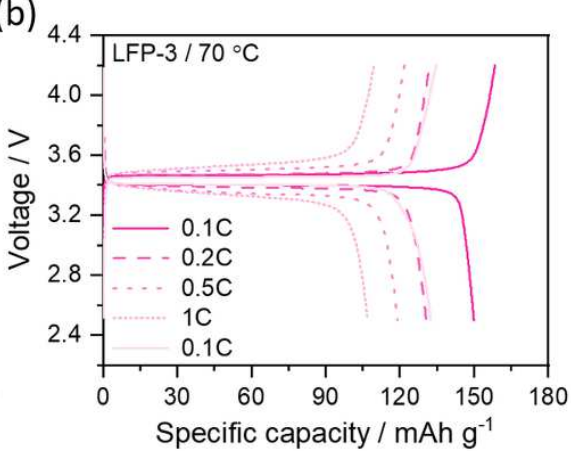

Figure 2. (a) comparative rate capability curve of LFP-1 to LFP-3 cathodes and (b) is the corresponding charge/discharge curves of LFP-3 cathode measured at $70^{\circ} \mathrm{C}$ at different current rates.

\section{Ball milling vs. magnetic stirring of slurry}

Now the slurry preparation process was varied and compared to study its influence using the selected EO:Li ratio of 12:1 on Li/SPNE/LFP cells. To understand the influence of LFP particle size on the electrochemical performance, we applied ball mill method on our standardized slurry preparation process. For this, two samples were comparatively studied, namely LFP-3 and LFP-4, where LFP-3 was obtained after magnetic stirring, whereas LFP-4 by a ball milling process. The exact compositions are kept the same and are described in table 2 . It is reported in the literature (for liquid electrolyte batteries) that the ball milling method helps in decreasing the particle size and also increase the homogeneity of active particles throughout the electrode ${ }^{23,24}$. For this study, the electrode composition of LFP-3 is used as a standard and the resulting mixture was ball-milled for $2 \mathrm{~h}$ (Table 2). The detailed method of preparation is given in the experimental section. SEM analysis were carried out after solvent casting and drying the electrodes on carbon-coated aluminium substrates. Figure $3 \mathrm{a}$ and $3 \mathrm{~b}$ shows a comparative SEM images of calendered LFP-3 and LFP-4 electrodes. It is clearly observed from the SEM images that the particle size of LFP decreases during the ball milling process and also increases the uniformity of all the components in the cathode LFP-4. This directly influences the electrochemical performance as shown in the figure 3c. The Li/SPNE/LFP-4 cell delivered high initial discharge capacity of $137 \mathrm{mAh} \mathrm{g}^{-1}$, in comparison to $\mathrm{Li} / \mathrm{SPNE} / \mathrm{LFP}-3$ cell $\left(115 \mathrm{mAh} \mathrm{g}^{-1}\right)$ at $1 \mathrm{C}$ rate at $70{ }^{\circ} \mathrm{C}$. The enhanced electrochemical performance of Li/SPNE/LFP-4 cell could be attributed to the smaller LFP particles which increases the Li ion diffusion as well as electron percolation pathways more efficiently at high current rate. The influence of cathode particle size on the electrochemical performance of SS-LMB has been recently studied by strauss et al., ${ }^{19}$ and reported that the ionic conductivity is not affected by the particle size, but the electronic conductivity is drastically increased by 3 orders of magnitude by decreasing the particle size from $15.6 \mu \mathrm{m}$ to $4.8 \mu \mathrm{m}$. In the present study, even after 50 cycles the Li/SPNE/LFP-4 cell delivered the high discharge capacity of $109 \mathrm{mAh} \mathrm{g}^{-1}$ in comparison to $\mathrm{Li} / \mathrm{SPNE} / \mathrm{LFP}-3$ cell with a capacity value of $77 \mathrm{mAh} \mathrm{g}^{-1}$ after 50 cycles. This result infers that the ball milling is one of the efficient methods for the preparation of cathode slurry for SS-LMB, which helps in decreasing the particle size as well as increases the contact area between particles and thereby improving the overall electrochemical performance of the cell even at higher current rates. 
Table 2. Influence of the slurry preparation method $(\mathrm{EO}: \mathrm{Li}=12: 1)$ on electrochemical performance. The batteries were tested at $1 \mathrm{C}$ at $70{ }^{\circ} \mathrm{C}$ for 50 cycles using Li/SPNE/LFP configuration.

\begin{tabular}{cccccc}
\hline Sample & Cathode composition & Method & $\begin{array}{c}\text { Initial capacity } \\
\left(\mathrm{mAh} \mathrm{g}^{-1}\right)\end{array}$ & $\begin{array}{c}\text { Final capacity } \\
\left(\mathrm{mAh} \mathrm{g}^{-1}\right) \\
\text { at } 50^{\text {th }} \text { cycle }\end{array}$ \\
\hline LFP-3 & LFP : CB : PEO : LITFSI & $63: 7: 19.4: 10.6$ & Magnetic stirring & 115 & 77 \\
LFP-4 & LFP : CB : PEO : LITFSI & $63: 7: 19.4: 10.6$ & Ball milling & 137 & 109 \\
\hline
\end{tabular}

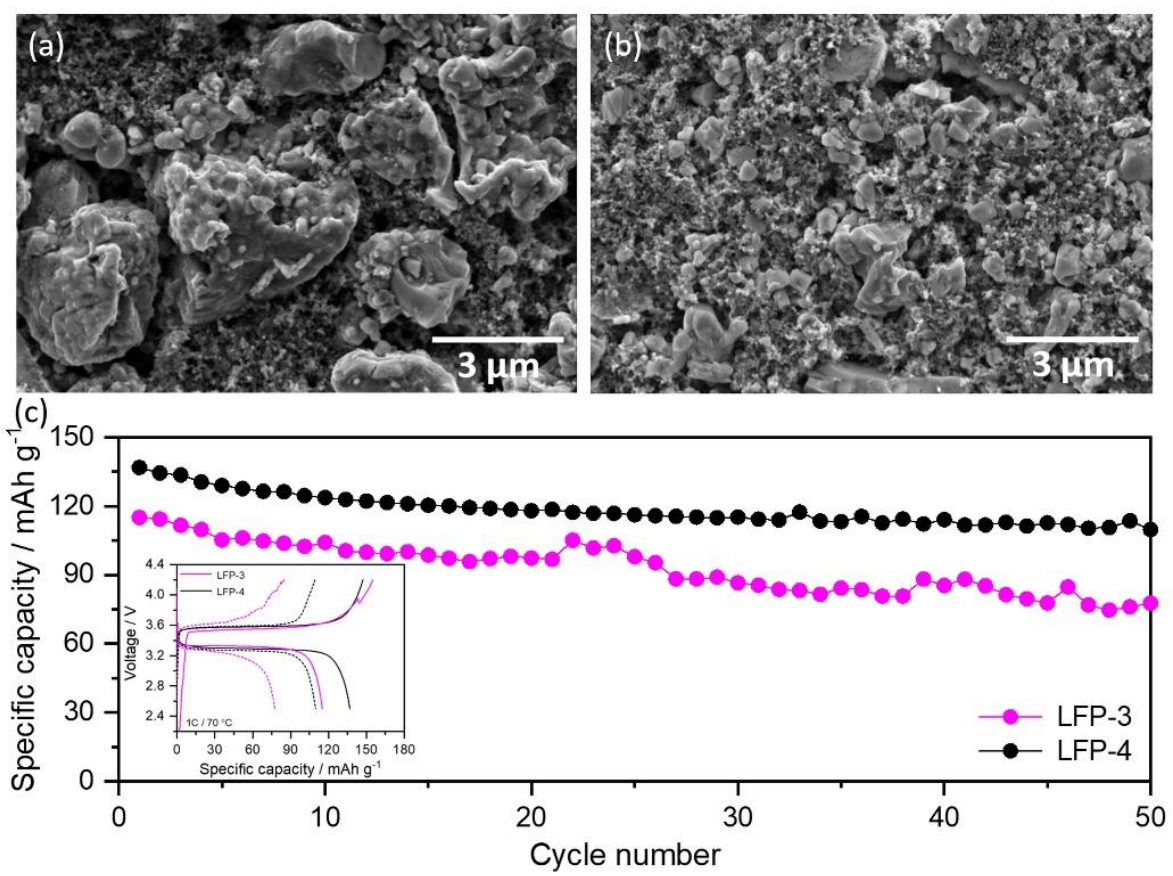

Figure 3. (a) and (b) are the SEM images of calendered LFP-3 and LFP-4 cathodes prepared by using magnetic stirring and ball milling processes, (c) comparative cycle performance curves of LFP-3 and LFP-4 cathodes measured at $70{ }^{\circ} \mathrm{C}$ at $1 \mathrm{C}$ rate with inset of their corresponding charge-discharge curves for the $1^{\text {st }}$ and $50^{\text {th }}$ cycles.

\section{Nature of conductive additives: Super $\mathbf{C 6 5}$ conductive carbon black vs. conductive graphite:}

Further, we also studied the influence of different electrically conductive additives (super C65 conductive carbon black, CB and conductive graphite, CG) and their weight ratios on the electrochemical performance of LFP cathode for SS-LMBs. It is reported in the literature for liquid based LIB system that the addition of graphite to LFP cathode helps in increasing the density of the electrode in comparison with super P carbon alone ${ }^{8}$. In addition, the large graphite particle size provides better contact between the active LFP particles and increases the electron percolation pathways more efficiently during fast reaction kinetics. Therefore, in the present study we examined the influence of homogenously distributed graphite particles in LFP cathode in the following.

The total amount of super C65 conductive carbon black (CB) used during the preparation of LFP1-4 cathode is $7 \mathrm{wt} \%$. Therefore, the CB content is decreased systematically and the reduced amount is compensated by conductive graphite (CG) in the series, LFP5-7 and fully replaced by CG in LFP-8. The corresponding electrode compositions with different conductive additives are given in the Table 3. After fabricating the electrodes, all the samples were subjected to SEM analysis. Figure 4a shows selected SEM image of LFP-5, and all the other corresponding SEM images of LFP-4, LFP-6 to LFP-7 are given in the supporting information figure S3. It can be clearly observed from the SEM images that the graphite particles (black) are distributed throughout the electrode and are in contact with the surrounding LFP particles (grey). The SEM cross sectional image of LFP-5 shown in Figure 4b, further supports the uniform distribution of graphite particles in the electrode. As a result of this, the LFP-5 to LFP-7 cathodes also (figure 4c) delivered high initial discharge capacities of $141 \mathrm{mAh} \mathrm{g}^{-1}, 134$ $\mathrm{mAh} \mathrm{g}^{-1}$, and $135 \mathrm{mAh} \mathrm{g}^{-1}$ which are comparable to that of LFP-4 (136 $\left.\mathrm{mAh} \mathrm{g}^{-1}\right)$ and retained the capacity values of $128 \mathrm{mAh} \mathrm{g}^{-1}, 120 \mathrm{mAh} \mathrm{g}^{-1}$, and $106 \mathrm{mAh} \mathrm{g}^{-1}$, respectively at $1 \mathrm{C}$ rate at $70^{\circ} \mathrm{C}$. However, the LFP-8 delivered 
comparably the lowest discharge capacities of $76 \mathrm{mAh} \mathrm{g}^{-1}$ at $50^{\text {th }}$ cycle. Therefore, the present results infer that the conductive graphite particles which are in close contact with the LFP particles help in increasing the electron transport pathways with the aid of $\mathrm{CB}$ particles to the current collector and improves active material utilization. However, the high surface area and high porous structure of $\mathrm{CB}$ and high dense structure of CG alone in the electrode (LFP-8) reduces the electron percolation pathways which leads to low specific capacity value. Among them, the LFP-5 cathode with about $2 \mathrm{wt} \%$ of CG and 5wt\% of CB additives in the electrode (figure 4d and 4e) evolved out to be the suitable weight ratio to achieve better electrochemical performance at high $\mathrm{C}$ rates, closely followed by the composition in LFP-6.
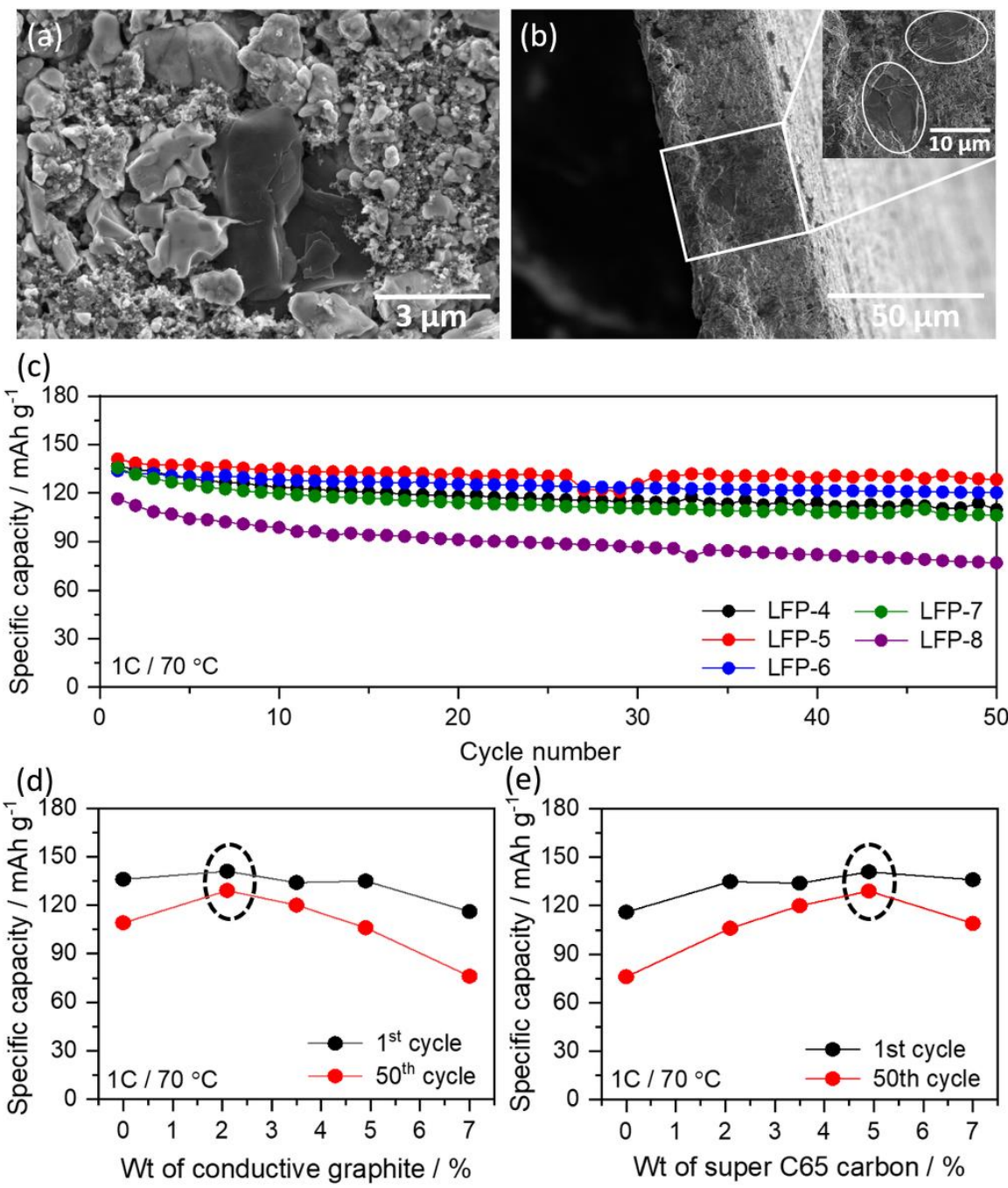

Figure 4. (a) and (b) are the SEM and cross-sectional image of LFP-5 cathode (c) comparative cycle performance of LFP-4 to LFP-8 cathodes measured at $1 \mathrm{C}$ rate at $70^{\circ} \mathrm{C}$, (d) and (e) are the comparative graph of specific capacity vs. weight of conductive additives in the electrodes. 
Table 3. Variation of conductive additives keeping EO: $\mathrm{Li}=12: 1$. The batteries were tested at $1 \mathrm{C}$ at $70{ }^{\circ} \mathrm{C}$ for 50 cycles using Li/SPNE/LFP configuration.

\begin{tabular}{|c|c|c|c|c|c|}
\hline \multirow{2}{*}{$\begin{array}{l}\text { Sample } \\
\text { LFP-4 }\end{array}$} & \multicolumn{2}{|c|}{ Cathode composition } & \multirow{2}{*}{$\begin{array}{c}\text { Method } \\
\text { Ball milling }\end{array}$} & \multirow{2}{*}{$\frac{\begin{array}{c}\text { Initial capacity } \\
\left(\mathrm{mAh} \mathrm{g}^{-1}\right)\end{array}}{136}$} & \multirow{2}{*}{$\begin{array}{c}\begin{array}{l}\text { Final capacity } \\
\left(\mathrm{mAh} \mathrm{g}^{-1}\right)\end{array} \\
\text { at } 50^{\text {th }} \text { cycle }\end{array}$} \\
\hline & LFP : CB : PEO : LITFSI & $63: 7: 19.4: 10.6$ & & & \\
\hline LFP-5 & LFP : CB : CG : PEO : LITFSI & $63: 4.9: 2.1: 19.4: 10.6$ & Ball milling & 141 & 128 \\
\hline LFP-6 & LFP : CB : CG : PEO : LITFSI & $63: 3.5: 3.5: 19.4: 10.6$ & Ball milling & 134 & 120 \\
\hline LFP-7 & LFP : CB : CG : PEO : LITFSI & $63: 2.1: 4.9: 19.4: 10.6$ & Ball milling & 135 & 106 \\
\hline LFP-8 & LFP : CG : PEO : LITFSI & $63: 7: 19.4: 10.6$ & Ball milling & 116 & 76 \\
\hline
\end{tabular}

Variation of LFP content in the cathode: Since all the above studies were carried out with a low amount of $63 \mathrm{wt} \%$ LFP, we also addressed the question of how to increase the LFP content and what are the consequences thereof. The active material content in the electrode plays an important role in deciding the specific capacity as well as specific energy of the cell. In this context, the only component which can be reduced is the amount of binder and therefore, we varied the LFP and binder content in the electrode by maintaining carbon and EO:Li (12:1) ratios as constant (as in LFP-5) and the respective electrode compositions are given in Table 4. Thus, LFP content was increased from 63 to $77 \mathrm{wt} \%$ from LFP-5 to LFP-10. Initially, the morphological studies were conducted on these electrodes and the corresponding SEM images are given in the supporting information figure S4. The SEM images of LFP-9 and LFP-10 cathodes also shows similar morphological appearance as LFP-5 cathode with the presence of graphite particles throughout the electrode with homogenous distribution. Though the FE-SEM shows similar type of morphological characteristics for all these electrodes, the electrochemical behaviour at $1 \mathrm{C}$ rate clearly differentiate the effect of active material content in the electrode. Figure 5a shows the comparative cycle performance curve of LFP-5, LFP-9 and LFP-10 cathodes measured at $1 \mathrm{C}$ rate at $70{ }^{\circ} \mathrm{C}$. It is interesting to observe from the figure 5a that the LFP-5/SPNE/Li cell showed the highest initial discharge capacity of $141 \mathrm{mAh} \mathrm{g}^{-1}$ and retained $128 \mathrm{mAh} \mathrm{g}^{-1}$ at $50^{\text {th }}$ cycle, in comparison to, Li/SPNE/LFP-9 cell $\left(131 \mathrm{mAh} \mathrm{g}^{-1}\right.$ at $1^{\text {st }}$ cycle, $105 \mathrm{mAh} \mathrm{g}^{-1}$ at $50^{\text {th }}$ cycle) and Li/SPNE/LFP-10 cell (51 $\mathrm{mAh} \mathrm{g}^{-1}$ at $1^{\text {st }}$ cycle, $46 \mathrm{mAh} \mathrm{g}^{-1}$ at $50^{\text {th }}$ cycle). The large differences in electrochemical behaviour can be understood as follows. At high LFP content of $77 \mathrm{wt} \%$ in LFP-10, the electron percolation pathways are high enough, but the lithium ion percolation pathways are worse due to low PEO/LiTFSI content, which leads to reduced capacity. On the other hand, the electrode polarization increases with increase in active material as shown in the figure $5 \mathrm{~b}$. Recently, Kimura et al ${ }^{25}$ has studied the influence of $55 \mathrm{wt} \%$ and $82 \mathrm{wt} \%$ of active material $\left(\mathrm{LiCoO}_{2}\right.$ cathode) loading on the electrochemical performance of inorganic solid electrolyte based LMB by using computed tomography combined with X-ray absorption near edge structure spectroscopy CT-XANES. This study reveals that the high active material loaded cell shows inhomogeneous reaction distributions due to aggregated active material particles, whereas, this behaviour is not observed in the cell with low active material loading. As a result, the cell with $55 \mathrm{wt} \%$ active material (see SI Figure S5) delivered high discharge capacity in comparison to the cell with high loading which leads to decreased ionic conductivity during redox process. A similar behaviour has been observed in the present study with increase in active material loading. Therefore, it is concluded from the electrochemical data that the optimum weight ratio of LFP, CB, CG, PEO and LiTFSI are 63, 4.9, 2.1, 19.4 and 10.6, respectively, in order to achieve better electrochemical performance at higher current rates (figure 5c). An increase in LFP content is possible only if the $\mathrm{Li}$-ion percolation in cathode is also equally maintained by using better polymer additives other than PEO.

SPNE thickness variation using LFP-5 cathode: In general, it is reported that the thickness of solid polymer electrolyte (SPE) decides the energy and power densities in SS-LMBs ${ }^{26}$. To verify this with respect to our best optimized cathode composition and morphology of LFP-5, we performed long-term cycle performance studies at higher current rate with different thickness of a polymer nanocomposite electrolyte containing $10 \mathrm{wt} \%$ $\mathrm{TiO}_{2}$ nanoparticles distributed in a PEO polymer matrix, referred to as $\mathrm{SPNE}^{27}$. The corresponding discharge capacity curves for three different thicknesses of SPNE $(40,90$ and $130 \mu \mathrm{m})$ for the first 500 cycles at $2 \mathrm{C}$ at $70^{\circ} \mathrm{C}$ are shown in figure $5 \mathrm{~d}$. It is interesting to note that with decreasing thickness of SPNE, the specific capacity and the cycle stability of the cell increase. This clearly indicates that the thickness of electrolyte has a huge influence on the electrochemical performance even with the standardized cathode. Even at $2 \mathrm{C}$, the cells retained capacity values of $82 \mathrm{mAh} \mathrm{g}^{-1}, 63 \mathrm{mAh} \mathrm{g}^{-1}$ and $28 \mathrm{mAh} \mathrm{g}^{-1}$ for the thickness of SPNE of $40 \mu \mathrm{m}, 90 \mu \mathrm{m}$ and $130 \mu \mathrm{m}$ even after 500 cycles, which indicates highest cycle stability of the cathode with the lowest SPNE thickness of $40 \mu \mathrm{m}$. 
In addition, we also studied the influence of temperature on the electrochemical behavior of the optimized LFP-5 cathode. Figure 6 shows the cycle performance of LFP-5 cathode measured at $0.2 \mathrm{C}$ at $30^{\circ} \mathrm{C}$ and the corresponding charge-discharge curves are given in the in-set of figure 6. Initially, the cells delivered high discharge capacity of $114 \mathrm{mAh} \mathrm{g}^{-1}$ and retained the capacity value of $96 \mathrm{mAh} \mathrm{g}^{-1}$ after 50 cycles. The high discharge capacity of Li/SPNE/LFP-5 cell is mainly due to optimum electrode composition as well as high lithium salt content in the electrode which acts as plasticizer and increases the overall lithium ion conduction pathways within the electrode at low temperature (supported by DSC of EO/Li $=12$; Figure S2). However, the Li/SPNE/LFP-5 cell at $30^{\circ} \mathrm{C}$ maintain a large overpotential of $620 \mathrm{mV}$ (in-set of figure 6), which is mainly due to high crystallinity of SPNE at low temperature $\left(30^{\circ} \mathrm{C}\right)$. The LFP content and the electrochemical performance of this cathode might be further improved by using novel polymer electrolytes with amorphous structure and high lithium ion transport number and ionic conductivity as additives to cathode.

Table 4. Variation of LFP content keeping EO: $\mathrm{Li}=12: 1$. The batteries were tested at $1 \mathrm{C}$ at $70{ }^{\circ} \mathrm{C}$ for 50 cycles using Li/SPNE/LFP configuration.

\begin{tabular}{cccccc}
\hline Sample & \multicolumn{2}{c}{ Cathode composition } & Method & $\begin{array}{c}\text { Initial } \\
\text { capacity } \\
\left(\mathrm{mAh} \mathrm{g}^{-1}\right)\end{array}$ & $\begin{array}{c}\text { Final capacity } \\
\left(\mathrm{mAh} \mathrm{g}^{-1}\right) \\
\text { at } 50^{\text {th }} \text { cycle }\end{array}$ \\
\hline LFP-5 & LFP : CB : CG : PEO : LITFSI & $63: 4.9: 2.1: 19.4: 10.6$ & Ball milling & 141 & 128 \\
LFP-09 & LFP : CB : CG : PEO : LITFSI & $70: 4.9: 2.1: 14.9: 8.1$ & Ball milling & 131 & 105 \\
LFP-10 & LFP : CB : CG : PEO : LITFSI & $77: 4.9: 2.1: 10.4: 5.6$ & Ball milling & 51 & 46 \\
\hline
\end{tabular}

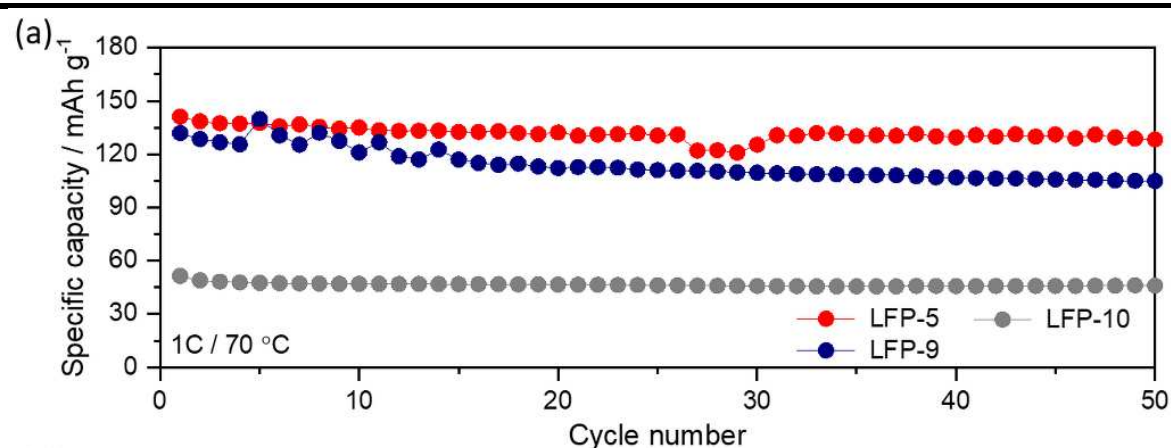

(b)
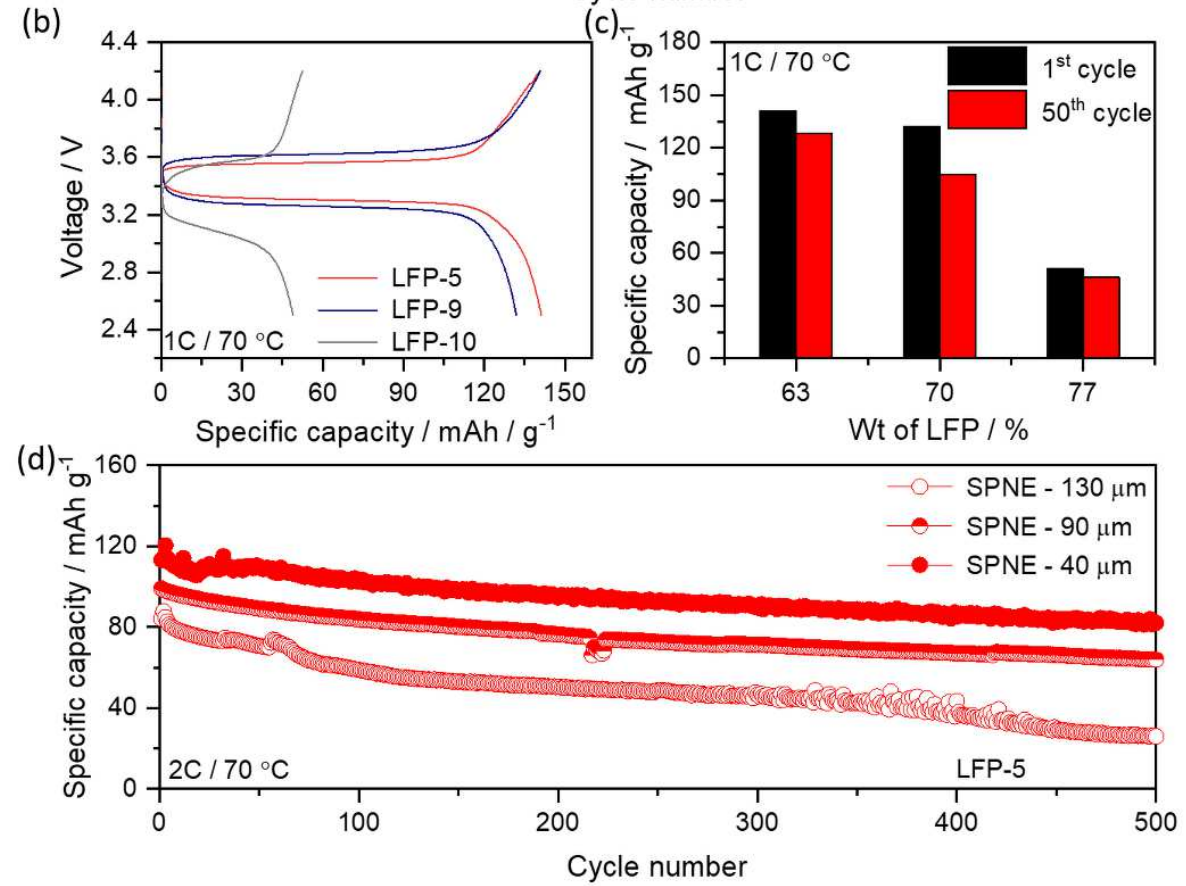

Figure 5. (a) Cycle performance curves of LFP-5, LFP-9 and LFP-10 cathodes measured at $1 \mathrm{C}$ rate at $70{ }^{\circ} \mathrm{C},(\mathrm{b})$ the corresponding first charge/discharge curves, (c) comparative specific capacity vs different weight ratios of 
LFP content in the electrode and (d) long-term cycle performance curve of LFP-5 cathode with different thickness of SPNE measured at $2 \mathrm{C}$ rate at $70^{\circ} \mathrm{C}$.

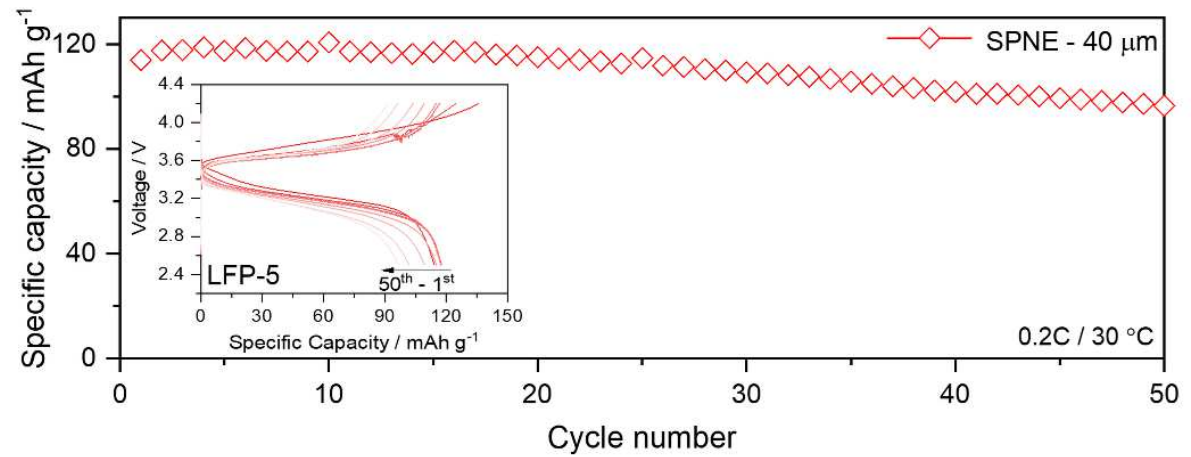

Figure 6. Cycle performance curve of LFP-5 cathode measured at $0.2 \mathrm{C}$ rate at $30{ }^{\circ} \mathrm{C}$ with in-set of its charge/discharge curves.

Though, the discharge capacity values delivered by the present LFP-5 cathode are comparable with the reported literature at low temperature $\left(30^{\circ} \mathrm{C}\right)$, superior discharge capacities are exhibited at high $\mathrm{C}$ rate (table 5 ). The excellent electrochemical performance of LFP-5 cathode at high current rates is attributed to the densification of electrode to form non-porous and crack-free architecture, small particle size of LFP via ball milling, incorporation of conductive graphite as additive and optimum active material, lithium salt and binder content in the electrode. This cathode can also be used as universal electrode for all PEG-based solid electrolytes. Furthermore, this electrode composition and morphology of each cathode system needs to be studied and optimized for other high operating voltage cathodes as well in combination of suitable electrolytes instead of PEO systems to make the SSLMB with high specific capacity and cycling stability feasible at room temperature.

\section{Conclusions}

In this study we have investigated the influence of conductive additives (such as super C65 conductive carbon black and conductive graphite) as well as cathode composition on the electrochemical performance of LFP cathode for high performing SS-LMBs. The application of ball milling during the slurry preparation helps in decreasing the LFP particle size and also increase the homogeneity throughout the electrode. Further, the SEM images reveal the significance of calendaring process in densifying the electrode to form a non-porous and crack-free structures. Among all the cathodes, LFP-5 with weight ratio of LFP $:$ CB $:$ CG $:$ PEO $:$ LiTFSI $=63: 4.9: 2.1: 19.4: 10.6$ delivered high discharge capacity of $141 \mathrm{mAh} / \mathrm{g}$ at $1 \mathrm{C}$ rate and retained $128 \mathrm{mAh} \mathrm{g}^{-1}$ upto $50^{\text {th }}$ cycle at $70{ }^{\circ} \mathrm{C}$. Thus, the present study reveals that the incorporation of $2 \mathrm{wt} \%$ conductive graphite helps in increasing the electron conduction pathways more efficiently within the electrode and enhances the overall electrochemical performance of the cell. When the current rate was switched to $2 \mathrm{C}$ the Li/SPNE/LFP- 5 cell delivered high discharge capacity $82 \mathrm{mAh} \mathrm{g}^{-1}$ even at $500^{\text {th }}$ cycle at $70{ }^{\circ} \mathrm{C}$. In addition, the cell also operates at low temperature of $30^{\circ} \mathrm{C}$ and delivered a high initial discharge capacity of $114 \mathrm{mAh} \mathrm{g}^{-1}$ and retained $84 \%$ of its initial capacity at $50^{\text {th }}$ cycle. The present results give the scope for the development of high performing SS-LMBs and the electrochemical performance of the LFP-5 cathode at low temperatures can be further enhanced by using novel amorphous solid electrolytes, additives and decreasing the solid electrolyte thickness. The future perspective for increasing the specific energy of the cell: 1) by increasing the active material content in the electrode using minimal amount of highly ion conductive medium (novel solid electrolytes), 2) increasing the thickness of electrode or 3) by using high operating voltage cathodes. 
Table 5. comparison of electrochemical performance of the present Li/SPNE/LFP-5 cell with those reported in the literature.

\begin{tabular}{|c|c|c|c|c|c|c|}
\hline \multicolumn{7}{|c|}{ Electrochemical measurements above the melting temperature of PEO $\left(>50^{\circ} \mathrm{C}\right)$} \\
\hline Cathode & $\begin{array}{l}\text { Act. Mater. } \\
\text { content }(\%)\end{array}$ & Electrolyte & $\begin{array}{l}\text { Cell testing } \\
\text { Temp. }\left({ }^{\circ} \mathrm{C}\right)\end{array}$ & $\begin{array}{l}\text { Final capacity } \\
\qquad\left(\mathrm{mAh} \mathrm{g}^{-1}\right)\end{array}$ & $\mathrm{C}$ rate & Ref. \\
\hline LFP & 70 & $\mathrm{PEO} / \mathrm{PMHS} / \mathrm{LiTFSI} / \mathrm{SiO}_{2}$ & 60 & $\begin{array}{c}121 \\
\left(50^{\text {th }} \text { cycle }\right)\end{array}$ & 0.1 & 28 \\
\hline LFP & 70 & $\mathrm{PEO} / \mathrm{LiTFSI} / \mathrm{Al}_{2} \mathrm{O}_{3}$ & 60 & $\begin{array}{c}136 \\
\left(300^{\text {th }} \text { cycle }\right)\end{array}$ & 0.2 & 29 \\
\hline LFP & 60 & $\mathrm{PEO} / \mathrm{LiClO}_{4} / \mathrm{SiO}_{2}$ & 55 & $\begin{array}{c}81 \\
\left(90^{\text {th }} \text { cycle }\right)\end{array}$ & 0.2 & 30 \\
\hline LFP & 60 & PEO/LiTFSI/PI & 60 & $\begin{array}{c}125 \\
\left(30^{\text {th }} \text { cycle }\right)\end{array}$ & 1 & 10 \\
\hline LFP & 70 & PEO/LiTFSI/TPU & 80 & $\begin{array}{c}119 \\
\left(100^{\text {th }} \text { cycle }\right)\end{array}$ & 1 & 31 \\
\hline LFP & 70 & $\mathrm{PEO} / \mathrm{LiTFSI} / \mathrm{Mg}_{2} \mathrm{~B}_{2} \mathrm{O}_{5}$ & 50 & $\begin{array}{c}120 \\
\left(250^{\text {th }} \text { cycle }\right)\end{array}$ & 1 & 14 \\
\hline LFP & 80 & $\mathrm{PEO} / \mathrm{PVDF} / \mathrm{LiTFSI} / \mathrm{Al}_{2} \mathrm{O}_{3}$ & 50 & $\begin{array}{c}\sim 110 \\
\left(30^{\text {th }} \text { cycle }\right)\end{array}$ & 1 & 32 \\
\hline LFP & 85 & $\mathrm{PEO} / \mathrm{LiTFSI} / \mathrm{Al}_{2} \mathrm{O}_{3}$ & 105 & $\begin{array}{c}100 \\
\left(260^{\text {th }} \text { cycle }\right)\end{array}$ & 1 & 33 \\
\hline LFP & 70 & $\mathrm{PEO} / \mathrm{LiTFSI} / \mathrm{Ni}_{3}-(\mathrm{BTC})_{2}$ & 70 & $\begin{array}{c}\sim 74 \\
\left(50^{\text {th }} \text { cycle }\right)\end{array}$ & 1 & 2 \\
\hline LFP-5 & 63 & PEO/LITFSI/P25 & 70 & $\begin{array}{c}128 \\
\left(50^{\text {th }} \text { cycle }\right)\end{array}$ & 1 & $\begin{array}{l}\text { This } \\
\text { work }\end{array}$ \\
\hline LFP-5 & 63 & PEO/LITFSI/P25 & 70 & $\begin{array}{c}82 \\
\left(500^{\text {th }} \text { cycle }\right)\end{array}$ & 2 & $\begin{array}{l}\text { This } \\
\text { work }\end{array}$ \\
\hline \multicolumn{7}{|c|}{ Electrochemical measurements below the melting temperature of PEO $\left(30^{\circ} \mathrm{C}\right)$} \\
\hline LFP & 60 & PEO/LiTFSI/PI & 30 & $\begin{array}{c}\sim 100 \\
\left(60^{\text {th }} \text { cycle }\right)\end{array}$ & 0.5 & 10 \\
\hline LFP & 80 & $\mathrm{PEO} / \mathrm{PVDF} / \mathrm{LiTFSI} / \mathrm{Al}_{2} \mathrm{O}_{3}$ & 30 & $\begin{array}{c}98 \\
\left(410^{\text {th }} \text { cycle }\right)\end{array}$ & 0.1 & 33 \\
\hline LFP & 70 & $\mathrm{PEO} / \mathrm{LiTFSI} / \mathrm{Mg}_{2} \mathrm{~B}_{2} \mathrm{O}_{5}$ & 30 & $\begin{array}{c}50 \\
\left(15^{\text {th }} \text { cycle }\right)\end{array}$ & 0.2 & 14 \\
\hline LFP-5 & 63 & PEO/LITFSI/P25 & 30 & $\begin{array}{c}96 \\
\left(50^{\text {th }} \text { cycle }\right)\end{array}$ & 0.2 & $\begin{array}{l}\text { This } \\
\text { work }\end{array}$ \\
\hline
\end{tabular}

\section{Methods}

\subsection{Materials:}

Standard $\mathrm{LiFePO}_{4}$ cathode, Super C65 conductive carbon black, conductive graphite and carbon-coated aluminium current collector was procured from MTI corporation. PEO $(50,00,000 \mathrm{~g} / \mathrm{mol})$, bis(trifluoromethanesulfonyl)imide lithium salt (LiTFSI, $99.95 \%)$ and lithium metal $(99.9 \%, 380 \mu \mathrm{m})$ are from Sigma Aldrich. Acetonitrile and n-methyl pyrrolidine are from Alfa Aesar and P25 ( $\mathrm{TiO}_{2}$ nanoparticles) was purchased from Degussa.

\subsection{Preparation of cathode slurry}

Initially, the cathode slurry was prepared according to the procedure reported in the literature ${ }^{21}$. Typically, the cathode composition of LFP, super 65 carbon, PEO and LiTFSI (EO/Li = 20:1) was maintained in the weight ratios of $63: 7: 22.7: 7.3$ and the resulting mixture was stirred overnight using acetonitrile as solvent $(50 \mathrm{ml}$ of acetonitrile is added for $1 \mathrm{gm}$ of PEO) to form an homogenous slurry. Then the resulting slurry was coated onto 
the carbon-coated aluminium current collector by using a doctor blade and then dried at room temperature for $4 \mathrm{~h}$. After drying at room temperature, the electrode was vacuum dried in the oven at $50{ }^{\circ} \mathrm{C}$ for overnight and the dried electrode was densified by calendaring machine (heat roll press machine, Model-TMAX-JS100; distance between the rolls was about $30 \mu \mathrm{m}$ and a constant roll temperature of $40{ }^{\circ} \mathrm{C}$ was maintained throughout the densification process). Finally, the electrodes were punched into the size of $14 \mathrm{~mm}$ diameter by using disc cutter and used for the fabrication cell. In the present study, we have also prepared different electrodes by reduced the solvent content to $75 \%$ (vol) as well as increased the lithium salt content (with different EO/Li ratios of 20:1, 16:1 and 12:1) during the cathode preparation to decrease the porosity in the electrode and to enhance the electrochemical performance.

Furthermore, ball milling method has been implemented in order to prepare the cathode slurry. For this, initially, $122.9 \mathrm{mg}$ of LiTFSI is dissolved in $8 \mathrm{ml}$ of Acetonitrile and stirred for 10 minutes to form a transparent solution. Then $226.9 \mathrm{mg}$ of PEO was added slowly to the above solution and stir for overnight. Weigh separately $733 \mathrm{mg}$ of LFP, $81.4 \mathrm{mg}$ of super C65 carbon and transfer it into a zirconia ball mail vial (with a capacity of $25 \mathrm{ml}$ ) and the above mixture of PEO-LiTFSI solution is added to it, so that the complete composition of the cathode corresponds to the weight ratio of 63:7:19.4:10.6. Finally, $0.5 \mathrm{ml}$ of NMP is added into the vial and then ball milled by using Retsch cryomill 200 for $2 \mathrm{~h}$ at room temperature with 10 minutes interval of resting time during each cycle. After milling, the cathode slurry was coated onto the C-coated aluminium current collector and follows the same procedure as mentioned above. Further, the cathode slurries with different weight percent of conductive graphite additive and with different electrode compositions (increasing the active material content) were also prepared by using ball milling process according to the electrode composition which are listed in table 3 and 4 .

\subsection{Preparation of PEO-LiTFSI-P25 electrolyte}

Initially, $10 \mathrm{wt} \%$ of $\mathrm{P} 25$ ( $\mathrm{TiO}_{2}$ nanoparticles) was dispersed in acetonitrile solution by using ultrasonication process for $1 \mathrm{~h}$. Then, LiTFSI salt is added to the above solution followed by adding PEO to it and stirred for overnight in order to have better homogeneity of P25 particles in the polymer matrix. The EO/Li ratio is maintained as $20: 1$ according to the literature report ${ }^{21}$, due to its good mechanical stability and high ionic conductivity. Then, the solution is poured into the petri dish and vacuum dried in the oven at $60{ }^{\circ} \mathrm{C}$ overnight. The self-standing solid polymer nanocomposite electrolyte (SPNE) with a thickness of $\sim 50 \mu \mathrm{m}$ and $16 \mathrm{~mm}$ dia., is prepared by hot-press machine and used for assembling the cells. In addition, three other different thickness such as $40 \mu \mathrm{m}, 90 \mu \mathrm{m}$ and $130 \mu \mathrm{m}$ was also prepared in the same way as mentioned above and used for comparative study at high $\mathrm{C}$ rate.

\subsection{Characterization}

The surface morphology all the electrodes were analysed by Scanning Electron Microscopy (SEM; Zeiss LEO 1530) and differential scanning calorimetry (DSC) measurements of PEO:LiTFSI with different EO/Li ratio of 12:1, 16:1 and 20:1 were performed on a Mettler Toledo DSC 3 at a heating rate of $10 \mathrm{~K} \mathrm{~min}^{-1}$ under nitrogen atmosphere.

\subsection{Electrochemical measurements}

The electrochemical performance of the prepared LFP cathodes were evaluated by using lithium metal as reference electrode and SPNE as solid electrolyte. All the cells were fabricated in argon filled glove box. Prior to the measurement, the cells were stabilised at $70^{\circ} \mathrm{C}$ for $12 \mathrm{~h}$ in order to have better contact between the electrodes and electrolyte. The galvanostatic charge-discharge and cycle performance measurements were conducted on

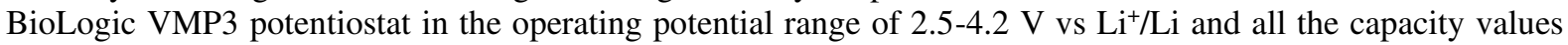
were calculated based on the active material (LFP) content in the electrode.

\section{References}

1. Xue, Z., He, D. \& Xie, X. Poly(ethylene oxide)-based electrolytes for lithium ion batteries, J. Mater. Chem. A, 3, 19218-19253 (2015).

2. Suriyakumar, S., Kanagaraj, M., Angulakshmi, N., Kathiresan, M., Nahm, K. S., Walkowiak, M., Wasinski, K., Polrolniczakc, P. \& Stephan, A. M. Charge-discharge studies of all-solid-state $\mathrm{Li} / \mathrm{LiFePO}_{4}$ cells with PEO-based composite electrolytes encompassing metal organic frameworks, RSC Adv., 6, 97180-97186 (2016).

3. Zhao, Y., Bai, Y., Li, W., An, M., Bai, Y., Chen, G., Design Strategies for Polymer Electrolytes with Ether and Carbonate Groups for Solid-State Lithium Metal Batteries, Chem. Mater. 32, 6811-6830 (2020).

4. Li, Z., Zhang, D. \& Yang, F. Developments of lithium-ion batteries and challenges of $\mathrm{LiFePO}_{4}$ as one promising cathode material, J Mater Sci., 44, 2435-2443 (2009). 
5. L. H. Hu, F. Y. Wu, C. T. Lin, A. N. Khlobystov, L. J. Li, Graphene-modified LiFePO4 cathode for lithium ion battery beyond theoretical capacity, Nature Communication, 4:1687

6. P. M. Pratheeksha, E. H. Mohan, B. V. Sarada, M. Ramakrishna, K. Hembram, P. V.V. Srinivas, P. J. Daniel, T. N. Rao, S. Anandan, Development of a novel carbon-coating strategy for producing core-shell structured carbon coated LiFePO4 for an improved Li-ion battery performance, Phys. Chem. Chem. Phys., 19, 175-188 (2017).

7. C. Meyer, H. Bockholt, W. Haselrieder, A. Kwade, Characterization of the calendering process for compaction of electrodes for lithium-ion batteries, Journal of Materials Processing Tech. 249, 172-178 (2017).

8. Zaghib, K., Shim, J., Guerfi, A., Charest, P. \& Striebel, K. A. Effect of carbon source as additives in $\mathrm{LiFePO}_{4}$ as positive electrode for lithium-ion batteries, Electrochemical and Solid-State Letters, 8, A207-A210 (2005).

9. Chen, Y. H., Wang, C. W., Liu, G., Song, X. Y., Battaglia, V. S. \& Sastry, A. M. Selection of conductive additives in Li-ion battery cathodes a numerical study, Journal of The Electrochemical Society, 154, A978A986 (2007).

10. Wan, J., Xie, J., Kong, X., Liu, Z., Liu, K., Shi, F., Pei, A., Chen, H., Chen, W., Chen, J., Zhang, X., Zong, L., Wang, J., Chen, L.Q., Qin, J., Cui, Y., Ultrathin, flexible, solid polymer composite electrolyte enabled with aligned nanoporous host for lithium batteries, Nature Nanotechnology, 14, 705-711 (2019).

11. Zhang, D., Zhang, L., Yang, K., Wang, H., Yu, C., Xu, D., Xu, B. \& Wang, L. M. Superior blends solid polymer electrolyte with integrated hierarchical architectures for all-solid-state lithium-ion batteries, ACS Appl. Mater. Interfaces, 9, 36886-36896 (2017).

12. Lago, N., Calvo, O. G., Amo, J. M. L., Rojo, T. \& Armand, M. All-solid-state lithium-ion batteries with grafted ceramic nanoparticles dispersed in solid polymer electrolytes, ChemSusChem, 8, 3039-3043 (2015).

13. Yu, J., Wang, C., Li, S., Liu, N., Zhu, J. \& Lu, Z. Li ${ }^{+}$-containing, continuous silica nanofibers for high $\mathrm{Li}^{+}$ conductivity in composite polymer electrolyte, Small, 15, 1902729 (2019).

14. Sheng, O., Jin, C., Luo, J., Yuan, H., Huang, H., Gan, Y., Zhang, J., Xia, Y., Liang, C., Zhang, W., Tao, X., $\mathrm{Mg} 2 \mathrm{~B} 2 \mathrm{O} 5$ Nanowire Enabled Multifunctional Solid-State Electrolytes with High Ionic Conductivity, Excellent Mechanical Properties, and Flame-Retardant Performance, Nano Lett., 18, 3104-3112 (2018).

15. Wan, Z., Lei, D., Yang, W., Liu, C., Shi, K., Hao, X., Shen, L., Lv, W., Li, B., Yang, Q. H., Kang, F., He, Y. B., Low Resistance-Integrated All-Solid-State Battery Achieved by Li7La3Zr2O12 Nanowire Upgrading Polyethylene Oxide (PEO) Composite Electrolyte and PEO Cathode Binder, Adv. Funct. Mater. 2019, 29, 1805301.

16. Ann, J., Choi, S., Do, J., Lim, S., Shin, D., Effects of binary conductive additives on electrochemical performance of a sheet-type composite cathode with different weight ratios of LiNi0.6Co0.2Mn0.2O2 in allsolid-state lithium batteries, Journal of Ceramic Processing Research, 19, 1-6 (2018).

17. Wang, M. J., Wolfenstine, J. B. \& Sakamoto, J. Mixed electronic and ionic conduction properties of lithium lanthanum titanate, Adv. Funct. Mater., 30, 1909140 (2020).

18. Satyavani, T.V.S.L., Kiran, B. R., Kumar, V. R., Kumar, A. S., Naidu, S.V.., Effect of particle size on dc conductivity, activation energy and diffusion coefficient of lithium iron phosphate in Li-ion cells, Engineering Science and Technology, an International Journal, 19, 40-44 (2016).

19. Strauss, F., Bartsch, T., Biasi, L., Kim, A. Y., Janek, J., Hartmann, P. \& Brezesinski, T. Impact of cathode material particle size on the capacity of bulk-type all-solid-state batteries, ACSEnergyLett., 3, 992-996 (2018).

20. Appetecchi, G. B., Carewska, M., Alessandrini, F., Prosini, P. P. \& Passerini, S. Characterization of PEObased composite cathodes I. morphological, thermal, mechanical, and electrical properties, J. of The Electrochemical Society, 147, 451-459 (2000).

21. Judez, X., Piszcz, M., Coya, E., Li, C., Aldalur, I., Oteo, U., Zhang, Y., Zhang, Z., Rodriguez-Martinez, L.M., Zhang, H., Armand, M., Stable cycling of lithium metal electrode in nanocomposite solid polymer electrolytes with lithium bis(fluorosulfonyl)imide, Solid State Ionics, 318 95-101 (2018).

22. Marzantowicz, M., Krok, F., Dygas, J.R., Florjanczyk, Z., Zygadlo-Monikowska, E., The influence of phase segregation on properties of semicrystalline PEO: LiTFSI electrolytes, Solid State Ionics, 179, 1670-1678 (2008).

23. Li, C. C., Lin, Y.S., Interactions between organic additives and active powders in water-based lithium iron phosphate electrode slurries, Journal of Power Sources, 220, 413-421 (2012).

24. Cheon, S.E., Kwon, C.W., Kim, D.B., Hong, S.J., Kim, H.T., Kim, S.W., Effect of binary conductive agents in $\mathrm{LiCoO} 2$ cathode on performances of lithium ion polymer battery, Electrochimica Acta, 46, 599-605 (2000).

25. Kimura, Y., Fakkao, M., Nakamura, T., Okumura, T., Ishiguro, N., Sekizawa, O., Nitta, K., Uruga, T., Tada, M., Uchimoto, Y., Amezawa, K., Influence of Active Material Loading on Electrochemical Reactions in Composite Solid-State Battery Electrodes Revealed by Operando 3D CT-XANES Imaging, ACS Appl. Energy Mater. 3, 7782-7793 (2020). 
26. Wu, J., Yuan, L., Zhang, W,. Li, Z., Xie, X,. Huang, Y., Reducing the thickness of solid-state electrolyte membranes for high-energy lithium batteries, Energy Environ. Sci., 14, 12-36 (2021).

27. Croce, F., Appetecchi, G. B., Persi, L., Scrosati, B., Nature, 394, 456-458 (1988).

28. Li, Y. J., Fan, C. Y., Zhang, J. P. \& Wu, X. L. A promising PMHS/PEO blend polymer electrolyte for allsolid-state lithium ion batteries, Dalton Trans., 47, 14932-14937 (2018).

29. Wei, Z,. Ren, Y., Wang, M., He, J., Huo, W. \& Tang, H. Improving the conductivity of solid polymer electrolyte by grain reforming, Nanoscale Research Letters, 15, 122 (2020).

30. Tan, X., Wu, Y., Tang, W., Song, S., Yao, J., Wen, Z., Lu, L., Savilov, S. V., Hu, N. \& Molend, Preparation of nanocomposite polymer electrolyte via in situ synthesis of $\mathrm{SiO}_{2}$ nanoparticles in PEO, Nanomaterials, 10 , 157 (2020).

31. Tao, C., Gao, M.H., Yin, B. H., Li, B., Huang, Y. P., Xu G. \& Bao, J. J. A promising TPU/PEO blend polymer electrolyte for all-solid-state lithium ion batteries, Electrochimica Acta, 257, 31-39 (2017).

32. Chen, X., He, W., Ding, L. X., Wang, S. \& Wang, H. Enhancing interfacial contact in all solid state batteries with a cathode-supported solid electrolyte membrane framework, Energy Environ. Sci., 12, 938-944 (2019).

33. Croce, F., Fiory, F. S., Persi, L. \& Scrosati, B. A high-rate, long-life, lithium nanocomposite polymer electrolyte battery, Electrochemical and Solid-State Letters, 4, A121-A123 (2001).

\section{Acknowledgments}

This work was supported by Bavarian Center for Battery Technology (BayBATT), University of Bayreuth and Bavarian Ministry of State for Research and Arts under SolTech project.

\section{Authors contribution statement}

EH executed the experiments, plotted the results and drafted the manuscript. Mt supervised the project, and corrected the manuscript.

\section{Competing interests}

The authors declare no conflict of interest

\section{Additional information}




\section{Supplementary Files}

This is a list of supplementary files associated with this preprint. Click to download.

- ThelakkatSupportinginformation.pdf 